\title{
A Study on the Integration of Multiple Subjects in Financial Supply of Traditional Chinese Medicine for Long-term care
}

\author{
SU Bo ${ }^{1,}$ a, FENG Si-qi ${ }^{1, b}$, GUAN Cui-ling ${ }^{2,3, c}$ \\ ${ }^{1}$ School of Management, Hubei University of Traditional Chinese Medicine, Wuhan 430065, China \\ ${ }^{2}$ key research base of humanities and social sciences in Hubei Province - Research Center for Development of Traditional Chinese \\ Medicine \\ ${ }^{3}$ Hubei University of Traditional Chinese Medicine, Wuhan 430065, China
}

\begin{abstract}
China is a country with an aging population, and the social risks brought by the incapacitated elderly and demented elderly are constantly increasing. It is difficult for families to bear the financial burden of long-term care for the incapacitated elderly and demented elderly independently, so they must rely on external forces to provide financial support for long-term care. The advantages of Traditional Chinese Medicine in the treatment and rehabilitation of senile diseases are increasingly prominent, but there is still a lack of integration between Traditional Chinese Medicine services and long-term care of the elderly, which should guide social subjects to enter the field of long-term care of the elderly in Traditional Chinese Medicine. This paper analyzes the feasibility of " $3+1$ " model in which multiple subjects, such as family, government, market, charity and public welfare organizations, share the financial burden of long-term care for the incapacitated elderly and demented elderly, and studies the construction of an effective financial supply integration mechanism.
\end{abstract}

\section{Introduction}

China has accelerated its entry into an aging society. According to the data released by China Aging Development Foundation, the number of the elderly population in China is expected to exceed 400 million in 2050, accounting for more than $30 \%$ of the total population. Taking Hubei Province as an example, according to the data of the sixth national census, the population aged 60 and over is up to 8.89 million and has reached $15.4 \%$ of the total population, of which the population aged 65 and over has reached 5.838 million, accounting for $10.1 \%$ of the total population [1].

The incapacitated elderly and demented elderly generally have many basic diseases with long course. The principle "preventing the occurrence before disease, controlling the development of existing disease" of Traditional Chinese Medicine (hereinafter referred to as "TCM") can provide the elderly with continuous medical and health care services. However, the financial cost of caring for the incapacitated elderly and demented elderly is unpredictable, and the cost of TCM is much cheaper than that of Western Medicine. Therefore, it is necessary to study the multiple models of financial supply subjects and improve the service ability of TCM long-term care.

\section{Overview of the long-term care Service for the Aged with the Combination of Medical Treatment and Care}

\subsection{Advantages of TCM in the diagnosis and treatment of geriatric diseases and health care and rehabilitation of the elderly}

The long-term care service for the elderly is mainly for the treatment and rehabilitation of the incapacitated elderly and demented elderly. At present, China has established a five-level TCM service system at the provincial, prefecture or city, county, township and village levels, and the TCM service has basically reached the full coverage. Research shows that TCM has unique advantages in the treatment of cancer, hypertension, diabetes, cardiovascular and cerebrovascular diseases, Alzheimer's disease and other chronic diseases of high incidence in the elderly [2]. Through the internal and external use of TCM, acupuncture and massage, rehabilitation care and other means of treatment, the purpose of relieving the condition and recovering part of the body function of the incapacitated elderly and demented elderly can be achieved. 


\subsection{Low integration of TCM and the elderly long-term care services}

In recent years, China attaches great importance to the participation of TCM in the elderly care services. However, due to the lack of clear guidance of policies and the relatively low cost of TCM, in the process of promoting the combination of medical treatment and care, there is no distinctive LEC service system of TCM for the elderly. According to the traditional Chinese family concept and filial piety culture and history, most of the elderly live in families. Surveys show that $77.5 \%$ of the respondents choose to provide for the aged locally, $49.6 \%$ at home, $37.2 \%$ in community and $13.2 \%$ in nursing institution [3]. TCM health care can be arranged to improve its accessibility to the long-term care services for the incapacitated elderly and demented elderly.

\subsection{Financial problems existing in the long-term care service for the aged of TCM}

1). Low use level of financial allocation funds due to multi-head administrative management

The superior departments of medical institutions and nursing institutions that the government provides the service of "combination of medical treatment and care" are the Health Care Commission and the Civil Affairs Bureau respectively, while the medical insurance settlement is subordinate to the Human Resources and Social Security Department. The government's multi-head management leads to the fragmentation of the use of financial directional allocation funds, and also increases the communication cost and time cost of grass-roots units.

\section{2). Lack of medical security system module}

At present in China, the security model to meet the health characteristics of the elderly is missing in the basic medical security system, most of the elderly medical institutions and nursing institutions can not settle the LEC expenditure with the elderly medical insurance, and the fund turnover is difficult. The current medical security policy focuses on the treatment of diseases, but lacks corresponding financial security policy for the early prevention of disease and long-term care after the recovery.

3). The urgent implementation of financial sharing of LONG-TERM CARE

For a long time, the financial sharing of the incapacitated elderly and demented elderly is borne by the family, which causes heavy financial burden to the family and is difficult to sustain. In the long run, it will trigger social risks, and seeking external forces to share financial risks has become a problem that must be faced in the aging society trend.

\section{A Social Need for " $3+1$ " Multiple Financial Subjects to Provide long-term care for the Aged}

\subsection{Sharing of the expenditure risk of long-term care expenses by multiple financial subjects}

The financial expenses of the incapacitated elderly and demented elderly have the risk of uncertainty, so they need to absorb multiple financial subjects to form a pattern of "integration and sharing".

\subsection{Sharing of financial loss of long-term care by multiple subjects to reduce the family economic burden of the incapacitated elderly and demented elderly}

With the acceleration of the aging process of the population, it is an objective fact that the number of the incapacitated elderly and demented elderly is increasing. According to the data of the National Bureau of Statistics, the incapacitation rate and dementia rate of the elderly in China increase with the increase of age. The incapacitation rate of the elderly aged $65-79,80-89$, $90-99$ and over 100 years old is $5.5 \%, 15.6 \%, 34.1 \%$ and $51.7 \%$ respectively; the dementia rate is $4.8 \%, 17.1 \%$, $36.3 \%$ and $56.6 \%$ respectively (see Table 1 ), which can be estimated to reach 52.24 million in 2050 [4].

Table 1 Rates of incapacitation and dementia among the elderly of different ages

\begin{tabular}{|c|c|c|c|c|}
\hline & $\begin{array}{c}65-79 \\
\text { years old }\end{array}$ & $\begin{array}{c}80-89 \\
\text { years old }\end{array}$ & $\begin{array}{c}90-99 \\
\text { years old }\end{array}$ & $\begin{array}{c}\text { over 100 } \\
\text { years old }\end{array}$ \\
\hline $\begin{array}{c}\text { Incapacitation } \\
\text { rate }\end{array}$ & $5.5 \%$ & $15.6 \%$ & $34.1 \%$ & $51.7 \%$ \\
\hline Dementia rate & $4.8 \%$ & $17.1 \%$ & $36.3 \%$ & $56.6 \%$ \\
\hline
\end{tabular}

The cost of care for the incapacitated elderly and demented elderly will be increasing day by day. The modern family's miniaturization characteristics are not enough to bear, and the individual and family's ability to pay cannot be sustained for a long time. The indicators of capacity to pay include per capita income surplus and household income surplus. Take the estimated per capita cost of care for the incapacitated elderly and demented elderly in urban and rural areas in 2015-2050 as an example (see Table 2).

Table 2 The proportion of per capita care cost of the incapacitated elderly and demented elderly in urban and rural areas to the surplus of per capita income of individuals and families

\begin{tabular}{|c|c|c|}
\hline $\begin{array}{c}\text { Urban and } \\
\text { rural areas }\end{array}$ & $\begin{array}{c}\text { The proportion of per } \\
\text { capita care cost of the } \\
\text { incapacitated elderly } \\
\text { and demented elderly } \\
\text { to the per capita } \\
\text { income surplus of } \\
\text { individuals }\end{array}$ & $\begin{array}{c}\text { The proportion of the } \\
\text { per capita care cost of } \\
\text { the incapacitated elderly } \\
\text { and demented elderly to } \\
\text { the family's per capita } \\
\text { income surplus }\end{array}$ \\
\hline Urban areas & $220 \%$ & $70 \%$ \\
\hline Rural areas & $180 \%$ & $60 \%$ \\
\hline
\end{tabular}

From table 2, it can be seen that the per capita cost of care for the incapacitated elderly and demented elderly exceeds the capacity of individuals and families. In 
2015-2050, the per capita cost of care for the incapacitated elderly and demented elderly in urban areas was about 2.20 times of the per capita income of urban residents, accounting for about $70 \%$ of the per capita income of urban families; the per capita cost of care for the incapacitated elderly and demented elderly in rural areas was about 1.8 times of the per capita income of rural residents, accounting for about $60 \%$ of the remaining per capita income of rural households [5]. It is difficult for urban and rural families to meet the financial needs of long-term care for the incapacitated elderly and demented elderly.

\subsection{The requirement of improving the national governance system with " $3+1$ " multiple subjects sharing the financial expenses of long-term care}

The investment of medical care resources for the elderly in China is seriously insufficient, and an effective financing mechanism has not yet been established. The family and the government are the natural long-term cost bearers. Among other social members, commercial insurance companies will participate in the interest demand. The natural organizational attribute of charitable organizations is bound to form one of the multiple subjects. Because there are few channels for charitable organizations to obtain resources, they can only be used as the auxiliary of multiple financial subjects. Therefore, the "3 + 1" financial subject model composed of government, family, market and charitable organizations is more feasible, among which "1" refers to charitable organizations that play a complementary role.

\section{Integration of Multiple Subjects of Financial Supply of long-term care in Combination of Medical Treatment and Care.}

\subsection{Conditions for the integration of multiple financial subjects in long-term care}

\section{1). Achieving win-win in long-term care financial supply by multiple subjects}

In the process of " $3+1$ " financial supply, only by achieving win-win results, can each subject have the will of financial supply and the power to maintain lasting supply. Although each subject's own resources and interests are different, the negative social impact of long-term care financial risk has been gradually recognized. The integration of government subjects and other subjects can help reduce the financial burden of the government itself and enhance citizens' sense of national identity. Likely, the integration of family and other subjects will reduce the financial burden of the family, the integration of market and other subjects greatly reduces the cost of trust and marketing under the government's credit endorsement, and wins social and economic benefits. The integration of charitable organizations and other subjects is not only a supplement to other financial subjects in long-term supply, but also an expansion of social influence.

2). Clear responsibilities in long-term care financial supply by multiple subjects

The responsibility scope, boundary, power and obligation of " $3+1$ " subjects in the long-term care financial supply need to be clearly divided, emphasizing consultation and cooperation in the process of participation, maintaining the power and order of participation, and promoting the efficiency of financial supply.

\subsection{The multiple subjects pattern of financial supply for the elderly in China being taking shape}

In February 2013, Notice on Several Opinions concerning Deepening the Reform of the Income Distribution System by the State Council clearly stated that "China should establish and improve the subsidy system for the elderly living alone, incapacitated and so on with economic difficulties." The Law of the People's Republic of China on the Protection of the Rights and Interests of the Elderly implemented on July 1, 2013 stated that "The local people's governments at all levels shall give nursing subsidies to the elderly who can't take care of themselves for a long time and have financial difficulties according to their incapacitation degree" [6]. However, it is difficult to cover all the financial costs of long-term care for the elderly without a clear subsidy amount and proportion.

The government is engaged in the transition from post filling to pre-prevention, and takes on the financial risks of long-term care of the elderly through compulsory and institutionalized social insurance. Commercial insurance companies provide long-term pension insurance to share financial losses. As a supplementary force, charitable organizations are also growing, and become a part of solving social pension problems. China's old-age care has formed a multi-subject financial supply system with family as the main subject, national financial support, active participation of the market and charity supplement.

\subsection{A need for the integration degree of multiple subjects in long-term care financial supply to be further strengthened}

Financial multi-subject integration is a complex process. The "3 + 1" long-term care financial supply subjects are limited by their own goals and interests, showing low participation of each subject and insufficient motivation for resource investment. The multi-subject integration mechanism lacks the consistency of action, and does not form a four-dimensional integration state composed of the main role positioning, responsibility division, resource sharing and monitoring evaluation.

1). Clarifying the role orientation and responsibility division of each subject.

To clarify the responsibility boundary of each subject, and make it verifiable and quantifiable, is the key to 
strengthen the responsibility of each party and improve the execution of the subject. In the financial supply, first of all, it is necessary to clarify the role of each subject. In the current social structure of a strong country, the core role of the main subject should be the government with the standard allocation of resources and the unshirkable responsibility of financial supply for the elderly. The financial supply of long-term care is based on the blood relationship and social ethics of traditional Chinese culture, and the family is also an important financial undertaker. The orientation of the commercial subject of the market determines that its sustained financial supply power lies in resolving the financial risks of long-term care and obtaining the necessary economic benefits at the same time. The public welfare goals of social organizations such as charity and public welfare are consistent with those of financial supply, but they are limited to their own financial financing ability and can only be the financial supplement of long-term care.

The main subject of financial supply should divide the work scientifically, and define the responsibility boundary, the role of the main subject and the capacity of resource supply. The government, which is in the core position, leads all subjects to pay attention to the incapacitated elderly and demented elderly. According to the principle of "managed competition", the government establishes financial financing channels to solve the financial pressure. The role and responsibility of the market is to expand the financing channels through the long-term care of commercial insurance, and attract more policyholders to provide financial compensation in the way of risk sharing. The role of charitable organizations is to give full play to their own advantages, to provide public welfare care services, or to purchase care services through financing channels.

2). Improving the efficiency of financial expenditure by connecting and sharing the main resources and strengthening the consistency of actions.

The government connects other subjects through policy making and resource allocation, and guides the subjects outside the government to provide long-term financial supply for the incapacitated elderly and demented elderly. Families can buy long-term or commercial care insurance from the government, and can also receive funds or services from charitable organizations. The market integrates with government, family and charitable organizations by providing commercial care insurance. Charity and public welfare organizations provide free economic assistance and care services for the incapacitated elderly and demented elderly, which penetrate into the government, families and markets. By promoting the integration and sharing of information of all subjects, strengthening the integration and utilization of big data, establishing the action reporting system of all subjects, and combining the health information and medical records of the elderly, China will form a comprehensive and systematic analysis, release and sharing channel of financial information of long-term care.

3). Strengthening the monitoring and evaluation of financial supply service of long-term care

The financial supply of long-term care involves income redistribution and interest adjustment of all subjects. China's laws and regulations in this regard are not perfect, and there is no clear division of the functions, responsibilities, rights and interests of all subjects in the financial supply. As a result, the mutual linkage mechanism of each subject in resource allocation, capital investment, data sharing has not been effectively formed, which can not guarantee the sustainability of financial supply for the incapacitated elderly and demented elderly. It is necessary to establish corresponding laws, policies, supervision and evaluation mechanisms, and bring the long-term care of the incapacitated elderly and demented elderly into the national governance system.

\section{Countermeasures and suggestions on the long-term care financial supply of multi-subject elderly care service}

\subsection{Strengthening the system of "combination of medical treatment and care" of TCM and improving the relevant fiscal and tax policies.}

Through the main subject linkage, the advantages of TCM will be brought into play in the long-term care of the incapacitated elderly and demented elderly in the "combination of medical treatment and care ", and the resources of TCM will be used to gather scientific research forces to strengthen the research on the prevention and treatment of long-term care of the incapacitated elderly and demented elderly [7]. With a series of incentive measures, the government can encourage many subjects to participate in the financial supply of long-term care of TCM. In the tax policy, the government can give pre tax deduction or individual income deduction for the items using TCM services, give tax deduction or preferential policies such as interest free loans and discount loans to enterprises providing long-term care products of TCM to the market and pension institutions. The government agencies should give support to land supply and public service facilities to reduce the burden and risk of financial subjects.

\subsection{Increasing financial policy support and encouraging medical insurance intervention}

In the Government Work Report of the two sessions in 2018, the reform of medical insurance payment was proposed, and the per capita financial subsidy standard of basic medical insurance for residents was increased by $¥ 40$ to $¥ 450$ [8]. In recent years, China has continued to deepen the reform of medical insurance, including the expenses incurred by the elderly in medical and nursing institutions into medical insurance, and encouraged commercial insurance companies to establish long-term care incapacitation and dementia insurance. It is suggested that insurance companies that use TCM pension insurance can enjoy more preferential financial support, such as policy support on the proportion and time of payment of medical insurance. 


\subsection{Establishing a dynamic financial service model to deal with long-term care of TCM for the incapacitated elderly and demented elderly.}

Dynamically explore the payment mode of TCM health care, guide more financial subjects to provide long-term care services of TCM. The whole long-term care system needs to form a moderately competitive market to help the incapacitated elderly and demented elderly get benefits from the competition. Through scientific mechanism design and system design, the government can realize the incentive compatibility of the stakeholders of the financial subject, give full play to the role of big data in information disclosure, monitoring and analysis, resource allocation, and social pressure relief, and finally realize the order of long-term service market and the rationalization of income distribution of medical service cooperation.

\section{CONCLUSION}

China's financial capital is not sufficient, the development of social aging is rapid, and the ability of family pension is limited. It is urgent to solve the problem of long-term care for the incapacitated elderly and demented elderly. It is of great value to solve the financial crisis of long-term care with " $3+1$ " financial multi-subject supply mode, which is helpful to relieve the pressure of family and society on providing for the aged. It has a long history to provide TCM diagnosis and treatment as well as appropriate rehabilitation technology to care for the incapacitated elderly and demented elderly, which is deeply favored by the people and has important economic and social value. The integration of multi-subject financial supply and health care of TCM plays an important role in promoting the healthy development of the aging society.

\section{Acknowledgement}

Fund project: key topic of education planning 2019 in Hubei Province-Innovation Research on the Undergraduate Talents Training Mode of Economic Management in Local Universities, 2019GA029.

\section{References}

1. Hubei Provincial Bureau of Statistics, Bulletin of national economic and social development statistics of Hubei Province [EB / OL], (October 1, 2014) (June 1,2018).

2. Si Fuchun, Song Xuejie, Gao Yan, Meng Xianpei. Analysis of the "Combination of Medicine and Nursing" Pension Model of Chinese Traditional Medicine [J]. Research on Chinese Traditional Medicine, 2016,29(08):1-3.

3. Geng Hui, Xu Yingjian, Yang Yang, Qian Qian Yan Hui, Tan Jia. Research on the Mode and Path of Care for the Aged Based on Combination of
Medicine and Nursing [J]. economic research guide, 2018(28):48-49+101.

4. Peng Chen, Wu Ming. Current situation of disability, dementia and long-term care for the elderly in China $[\mathrm{J}]$. Journal of Preventive Medicine of PLA, 2016,34(03):382-384+388.

5. Cao Xinbang. Research on the Integration Mechanism of Multi-subjects of Long-term Care Financial Supply in China [J]. China Administration, 2019(09):107-112.

6. Su Wen, Anal. Research on the Service of Five Guarantees in Rural and Pastoral Areas of Inner Mongolia [J]. Frontier, 2016(08):77-82.

7. Xiong Zhenfang, Zhang Chengpeng, Li Shengjie, Lu Wenliang. Analysis on the Current Situation of "Combination of Medical Care and Support" for the Elderly in Traditional Chinese Medicine-Taking Hubei Province as an Example [J]. Shi Zhenguo Medical and National Medicine, 2018,29(12):3064-3067.

8. China Net. Government work report [EB / OL] (March 22, 2018). 